\title{
A Marine Aerosol Reference Tank system as a breaking wave analogue for the production of foam and sea-spray aerosols
}

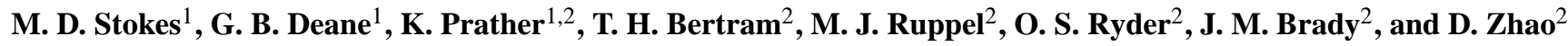 \\ ${ }^{1}$ Marine Physical Laboratory, Scripps Institution of Oceanography, La Jolla, CA, USA \\ ${ }^{2}$ Dept. of Chemistry and Biochemistry, University of California, San Diego, CA, USA
}

Correspondence to: M. D. Stokes (dstokes@ucsd.edu) and T. H. Bertram (tbertram@ucsd.edu)

Received: 15 October 2012 - Published in Atmos. Meas. Tech. Discuss.: 4 December 2012

Revised: 16 March 2013 - Accepted: 5 April 2013 - Published: 30 April 2013

\begin{abstract}
In order to better understand the processes governing the production of marine aerosols a repeatable, controlled method for their generation is required. The Marine Aerosol Reference Tank (MART) has been designed to closely approximate oceanic conditions by producing an evolving bubble plume and surface foam patch. The tank utilizes an intermittently plunging sheet of water and large volume tank reservoir to simulate turbulence, plume and foam formation, and the water flow is monitored volumetrically and acoustically to ensure the repeatability of conditions.
\end{abstract}

\section{Introduction}

Sea-Spray Aerosols (SSA) are critically important components in global biogeochemical cycles (e.g., Solomon et al., 2007) and important modifiers of atmospheric radiative budgets because they are generated over a large portion of the earth's surface and form a large fraction of aerosol particulates present in the atmosphere (e.g., Lewis and Schwartz, 2004). Marine aerosols are generated primarily by processes associated with the formation of bubble plumes and foams generated by the actions of breaking surface waves. Breaking waves themselves play an important role in many additional processes at the air-sea interface including mixing, current formation, heat and momentum flux, and the entrained bubbles enhance gas transport, scavenge biological surfactants, and generate ambient noise in addition to creating aerosol particles.

Oceanic whitecaps (the high optical albedo footprint of a breaking surface wave) typically form once wind speeds greater than approximately $3 \mathrm{~m} \mathrm{~s}^{-1}$ blow over a sea surface of appropriate fetch. Breaking itself includes the impaction of the overturning wave crest with the sea surface and subsequent entrainment and fragmentation of air into a plume of bubbles. The plume evolves over a timescale of seconds to a few tens of seconds due to buoyancy and turbulent flow forces acting on the entrained bubbles. The air-water mixture of the breaking wave crest and the bubbles that reach the sea surface after breaking form the high albedo patch characteristic of a whitecap. Surface bubbles and the dense aggregations of bubbles that create surface foams, are the primary source of marine aerosols as the bubbles rupture and produce a spray of jet and fluid film droplets that are ejected into the atmosphere.

In order to study marine aerosol production and whitecap bubble and foam dynamics, it would be beneficial to have a standardized method of creating them in repeatable, controlled conditions in the laboratory that accurately models the aerosols formed by breaking waves. Several different methods have been used to generate surrogate marine aerosols within enclosed tanks including pressurized atomizers (Svenningsson et al., 2006; Riziq et al., 2007; Saul et al., 2006; McNeill et al., 2006; Braban et al., 2007; Niedermeier et al., 2008; Taketani et al., 2009), forcing air through glass filters or sintered materials (Cloke et al., 1991; Martensson et al., 2003; Sellegri et al., 2006; Keene et al., 2007; Tyree et al., 2007; Wise et al., 2009; Hultin et al., 2010; Fuentes et al., 2010 ) and by a plunging water jet (Cipriano and Blanchard, 1981; Sellegri et al., 2006; Facchini et al., 2008; Fuentes et al., 2010).

The detailed investigations by Sellegri et al. (2006) and Fuentes et al. (2010) have shown that the best method for the laboratory generation of proxy marine aerosols is to create 
a bubble plume from a plunging jet of water. The method of generation used had a strong influence over the chemical and physical properties of the aerosols produced in including variation in organic enrichment, formation of condensation nuclei and variation in hygroscopicity (Fuentes et al., 2010) and bubbles generated by the plunging jet more closely approximated those from oceanic measurements. The plunging jet apparatus used by Fuentes et al. (2010) used a relatively small volume of water $(6 \mathrm{~L})$ in an $11 \mathrm{~L}$ tank filled to a depth of $11 \mathrm{~cm}$ and their investigations suggested that in order to better duplicate the characteristics of oceanic plumes (including bubble lifetime), the dimensions of current laboratory systems would have to be enlarged.

Here we show the fabrication of a Marine Aerosol Reference Tank (MART) system that can accurately reproduce the bubble plumes and marine aerosols characteristic of an oceanic whitecap. By using an intermittent plunging sheet of water in a larger $(210 \mathrm{~L})$ tank, bubble plumes are formed that mimic the size distribution, including critical bubbles larger than the Hinze scale (the transition point between bubbles stabilized by surface tension and bubbles subject to fragmentation by turbulence at approximately $1 \mathrm{~mm}$ ), and have a temporal evolution similar to plumes measured in the ocean and in large laboratory wave tanks. Because the production of the bubbles can be continuously monitored acoustically, and the physical and chemical conditions of the MART system can be carefully controlled, the resulting aerosols generated by these bubble plumes are not only very similar to natural marine aerosols, but they can also be duplicated in replicate experiments.

\section{Whitecap foam and bubble size distributions}

The two primary production mechanisms of sea-spray aerosols at moderate wind speeds are the disintegration of the thin fluid films associated with whitecap foam (film drops) and the break up of the jet of water formed at the base of a bubble shortly after the rupture of its film (jet drops). Both of these mechanisms are known to be sensitive to bubble size. It follows that an essential requirement of any laboratory system designed to produce nascent SSA is the reproduction of the numbers and sizes of bubbles entrained by breaking waves in the open ocean. Few bubble size distributions from natural breaking waves have been acquired because of the difficulty of making measurements in stormy conditions and other natural hazards (Herrero, 1985; Melville, 1996; de Leeuw and Cohen, 2002; Stokes et al., 2002). However, some oceanic measurements are available in addition to a number of laboratory studies (e.g., Monahan and Zeitlow, 1969; Cipiriano and Blanchard, 1981; Bezzabotnov et al., 1986; Lamarre and Melville, 1994; Loewen et al., 1995; Leighton et al., 1996; Deane and Stokes, 2002; de Leeuw and Cohen, 2002; de Leeuw and Leifer, 2002; Leifer and de Leeuw, 2002, 2006; Stokes et al., 2002). Measurements

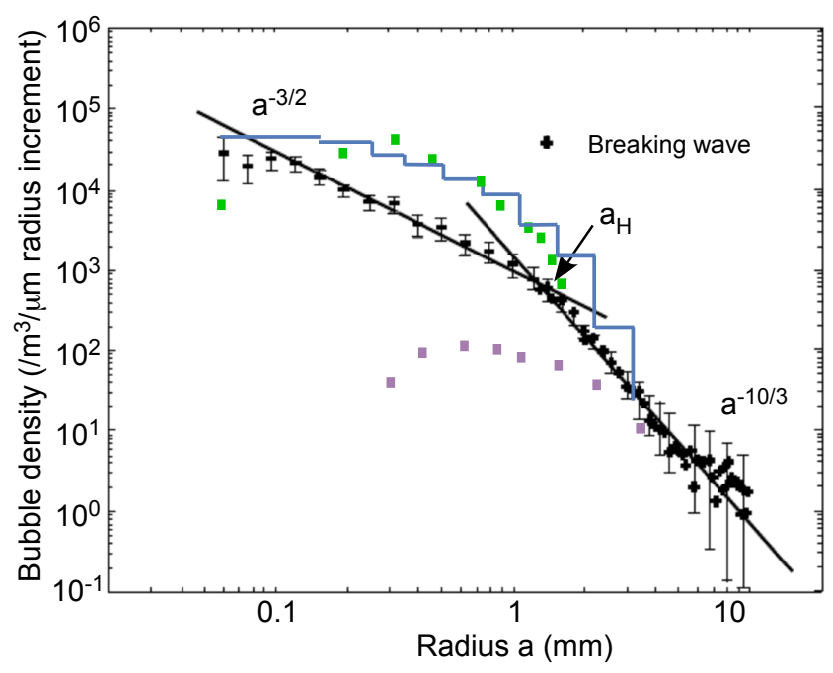

Fig. 1. Bubble size distribution (density vs. bubble radius) in open ocean and laboratory whitecaps. The grey lines show reference power law scalings for bubble distributions. Theoretical considerations lead to an $a^{-10 / 3}$ power law scaling for bubbles larger than the Hinze scale (approximately $1 \mathrm{~mm}$ ). Bubbles smaller than the Hinze scale are more variable in their power law scaling but roughly follow an $a^{-3 / 2}$ trend (Deane and Stokes, 2002). Purple squares are Loewen et al. (1995), green, Bezzabotonov et al. (1986) and blue line from Cirpriano and Blanchard (1981).

of bubble size distributions within whitecaps in two oceanic studies and a laboratory study are shown in Fig. 1. It is now known that there is a scale dependence to the bubble creation physics, differentiated by a length scale known as the Hinze scale (Deane and Stokes, 2002). The Hinze scale $\left(a_{\mathrm{H}}\right)$ defines the radius of a bubble for which surface tension forces, which tend to keep bubbles spherical, are balanced by distorting forces associated with fluid turbulence. This scale is of the order of $1 \mathrm{~mm}$ in spilling and breaking waves. Bubbles smaller than the Hinze scale are stabilized to fragmentation by fluid turbulence, whereas bubbles larger than this scale are subject to a turbulent fragmentation cascade.

The power law dependence of the bubble size distribution as a function of bubble radius is also different for bubbles smaller and larger than the Hinze scale. Smaller bubbles have a somewhat variable power law scaling, $a^{-n}$ with $n$ taking values between approximately 1 to 2 . This variability can be seen in measured distribution slopes for bubbles smaller than $a_{\mathrm{H}}$ in Fig. 1. The physics of bubble fragmentation and bubble degassing drives a steeper power law dependence for bubbles larger than the Hinze scale with $\mathrm{n}$ taking values between approximately 3 to 4 (Fig. 1). The two relevant points here are (1) breaking waves can produce large bubbles, greater than $1 \mathrm{~mm}$ radius and up to $4 \mathrm{~mm}$ radius (Bowyer, 2001), and (2) the power law scaling of the generation of these bubbles is controlled by fluid turbulence within the whitecap and differentiated by the Hinze scale. In order to accurately reproduce 
nascent SSA, the laboratory bubble generation mechanism needs to produce bubbles larger than the Hinze scale and reproduce the power law dependence those bubbles acquire through fragmentation in fluid turbulence. The large bubbles are important because the film-drop and jet drop SSA production mechanisms are scale-dependent. It is generally accepted that film drops are produced by bubbles larger than roughly $1 \mathrm{~mm}$ radius (e.g., see Fig. 30 in Lewis and Schwartz, 2006), whereas jet drops are produced in quantities greater than 1 per bubble by bubbles less than $1.5 \mathrm{~mm}$ radius (see Fig. 26 in Lewis and Schwartz, 2006). Physical production mechanisms that do not reproduce bubbles at the large end of the spectrum will therefore preferentially enhance jet drop over film drop production in comparison with the ratio expected from breaking waves. Exactly to what extent the SSA production processes will be biased is complicated by the fact that bubbles floating on the surface have a different and surfactant-dependant shape from that of rising bubbles (Nicolson, 1949) and, once on the surface, foam coarsens through a process of bubble coalesce which creates films of increasing scale (Saint-James, 2006).

\section{The Marine Aerosol Reference Tank (MART)}

The MART system was constructed to closely mimic the bubble plume, foam, and aerosol generating mechanisms active during oceanic wave breaking and to provide a portable, controllable environment in which to explore and sample these processes. The primary design of the system includes a flow-controlled closed-loop seawater (or freshwater) circulation system that draws from the tank bottom, a tank-top spillway or waterfall to produce a plunging sheet that impacts the water surface within the tank to produce a bubble plume, and an air-tight headspace for controlled aerosol sampling while the system is operating. Instrumentation (flow meter, acoustic monitoring) is incorporated into the design to insure plume generation consistency during long experimental runs and repeatability over separate experimental setups. By varying the temperature of the tank contents, the water chemistry and the characteristics of the plunging sheet (volume, angle and distance of drop, timing of the intermittency) a wide range of experimental conditions can be realized.

The MART system (Fig. 2) was fabricated using components that are readily available and constructed of stainless steel, plexiglass and silicone wherever possible to minimize chemical contaminates and facilitate cleaning. The tank was modified from a $210 \mathrm{~L}$ plexiglass aquarium (AquaClear) that was drilled to accept an o-ring sealed, $20 \mathrm{~mm}$ thick plexiglass lid to provide airtight integrity. All fittings were attached to the tank through threaded bulkheads made from $25 \mathrm{~mm}$ thick plexiglass plates, tapped to accept standard stainless steel pipe fittings (NPT-thread). In order to minimize flow resistance and maximize pump efficiency, the circulation system was designed with short pipe lengths and large internal

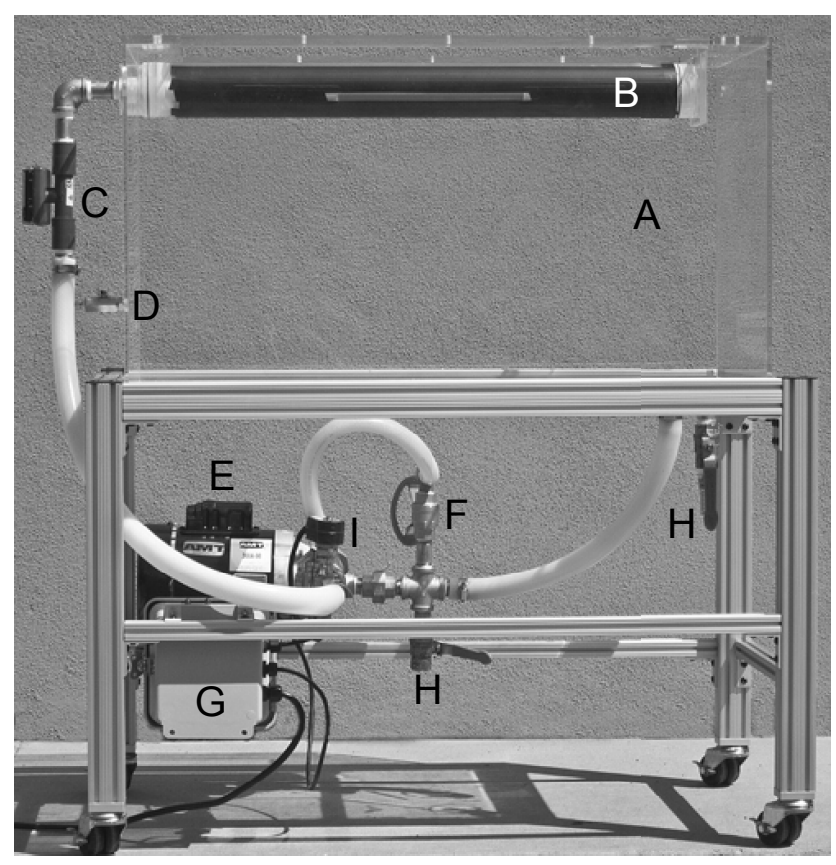

Fig. 2. Marine Aerosol Reference Tank (MART). The $210 \mathrm{~L}$ plexiglass tank (A) is approximately $1 \mathrm{~m}$ in the longest dimension. (B) The internal water distribution assembly is o-ring sealed with central spillway slot. Inside the assembly is a secondary diffuser tube (not visible) for evenly distributing the water along the spillway. (C) Flow meter. (D) Tank water sampling spigot. (E) 1/3 HP Centrifugal pump. (F) Flow shunt control valve. (G) Timing relay control box. (H) Tank drain and purge valves. (I) Solenoid valve.

diameter (20-25 mm) fittings. Pumping was provided by a $1 / 3$ HP centrifugal pump (AMT Pumps) capable of pumping more than $70 \mathrm{~L} \mathrm{~min}^{-1}$ and powered by $110 \mathrm{~V}$ electric motor. A valved shunt in the circulation loop allows the regulation of the return flow to the tank between approximately $15 \mathrm{~L} \mathrm{~min}^{-1}$ and the maximum pumping rate, and is monitored using an in-line flow meter (GPI products TM-15). The intermittency of the tank return flow is regulated using a solenoid valve (Parker Fluid Controls J5011) controlled by two time-delay relays (Macromatic TR53122) adjustable between 0 and $10 \mathrm{~s}$. Separate ports are available for sampling both the atmospheric headspace and subsurface water in the tank. All electric motor controls and the solenoid timer relays are contained in a water resistant box for protection. At present, the MART system is mounted to a wheeled aluminum chassis for easy portability.

Water that enters the tank is formed into a plunging sheet that impacts the water surface to mimic the plunging jet of water from a breaking wave crest (Fig. 3). The water exiting the pump system is channeled through an o-ring sealed plexiglass tube approximately $8 \mathrm{~cm}$ internal diameter that contains a secondary internal diffuser $(3 \mathrm{~cm}$ diameter tube with holes spaced at regular $2 \mathrm{~cm}$ distances along its length) to evenly distribute the water within. Water exits this nested 


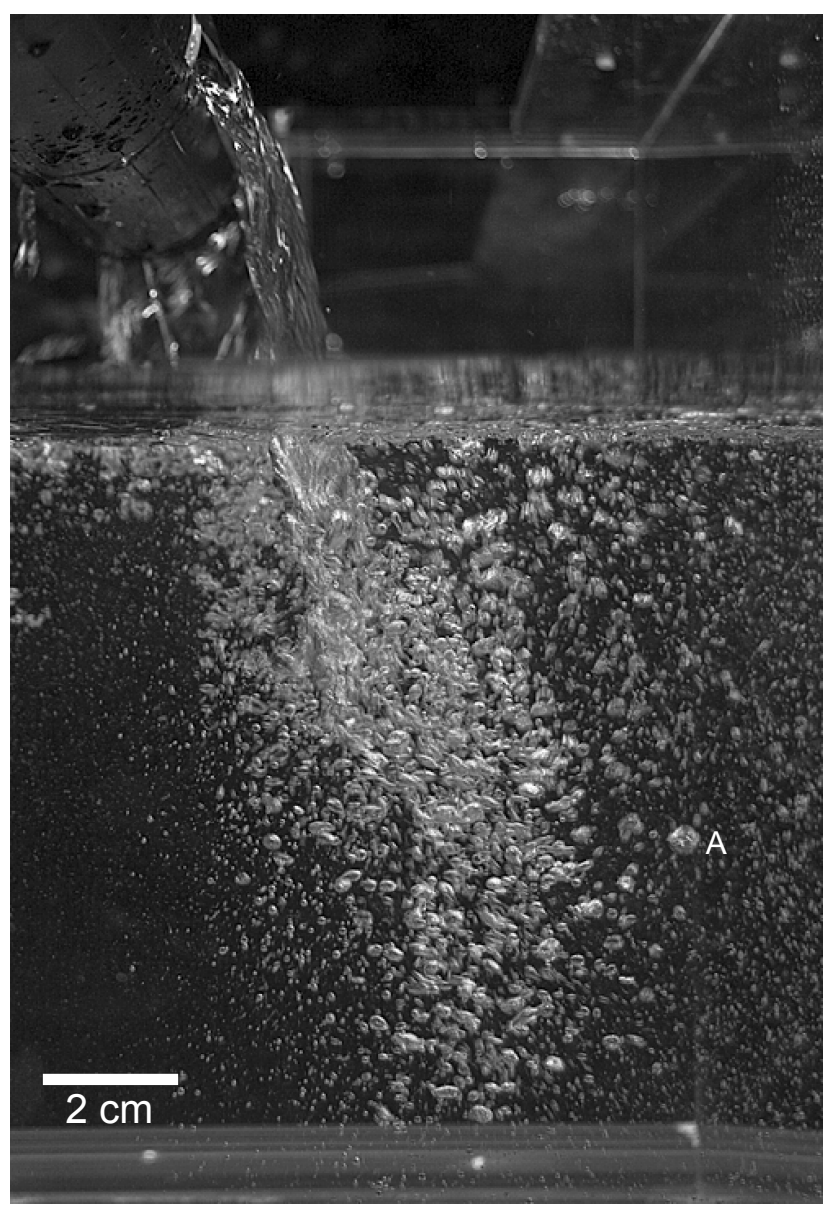

Fig. 3. Side view of plunging sheet and bubble plume. Bubble A is approximately $2.2 \mathrm{~mm}$ in radius, demonstrating the presence of bubbles larger than the Hinze scale. The free-fall distance between the exit slot of the waterfall and the water surface is approximately $10 \mathrm{~cm}$, but appears shorter due to the angle at which the photograph was taken. The width of the plunging sheet is approximately $20 \mathrm{~cm}$.

tubing through an approximately $6 \mathrm{~mm}$ wide $\times 20 \mathrm{~cm}$ long slot in the outer tube and plunges as an approximately $1 \mathrm{~cm}$ thick sheet before impacting the surface of the water. In the configuration described here, the water level within the tank was kept constant to provide an approximately $10 \mathrm{~cm}$ drop between the plunging sheet and surface, producing a bubble plume penetrating about $25 \mathrm{~cm}$ beneath the surface and bubbles in a wide range of sizes up to about $1 \mathrm{~cm}$ in diameter. Above the rising bubble plume, a surface patch of foam is produced, with time-evolving characteristics depending on the water temperature, salinity and presence of surfactants in the tank. By using filtered seawater in a $3 \mathrm{~s}$ flowing sheet followed by an $8 \mathrm{~s}$ pause to allow plume degassing and foam creation, a surface patch of foam cells approximately 10$15 \mathrm{~cm}$ wide by $30 \mathrm{~cm}$ in length was created and decayed in about 5-6s. In addition, the length of the spillway slot can be varied depending on the experimental requirements as can the number of slots in the spillway. For example, a single slot was used to examine plume and foam patch characteristics, and a two slot configuration (with the slots at $180^{\circ}$ along the length of the spillway) has been used to maximize the generation of aerosols during a plunging event.

Before experimentation the MART system is cleaned to minimize contamination. The internal tank surfaces are scrubbed with $100 \%$ percent isopropanol and then the entire system is filled and the pump and spillway circulated with a $10 \%$ isopropanol/deionized water solution for approximately $30 \mathrm{~min}$. After circulation the tank is drained and then rinsed with deionized water, and the system again circulated. Lastly, the system is flushed with filtered freshwater (or seawater) and circulated while the tank water level is held constant by balancing the water input and tank drain flow rates. The MART system is considered clean when measurements of surface tension from tank water samples are the same as those from the filtered water supply used for experimentation (approximately $72 \mathrm{mN} \mathrm{m}^{-1}$ measured using the Wilhemy plate method with a Krüss K3 tensiometer.) Although it has been possible to sufficiently clean the MART system with its mix of different construction materials (primarily plexiglass and stainless steel), the design is simple enough that an entire system could potentially be fabricated almost entirely of stainless steel and glass should more aggressive cleaning be required.

\subsection{Bubble size distribution measurements}

To examine the utility of the MART system as an oceanic bubble plume proxy, the size distributions of bubbles within the tank plumes were compared to those produced by sintered glass filters as well as to oceanic and laboratory wave channel distributions. The glass filters were set at a depth of $\sim 25 \mathrm{~cm}$ (filter surface to water surface) and dry nitrogen gas $\left(0.5 \mathrm{~L} \mathrm{~min}^{-1}\right)$ was pumped through four filters, two $90 \mathrm{~mm}$ diameter type $\mathrm{E}$ filters and two $25 \mathrm{~mm}$ diameter type A filters, similar to the setup of Keene et al. (2007). The plunging sheet peak flow rate was approximately $1 \mathrm{~L} \mathrm{~min}^{-1}$, falling through a height of approximately $10 \mathrm{~cm}$, and modulated with on/off times of approximately $4 \mathrm{~s}$ on and $10 \mathrm{~s}$ off.

The sintered glass filter and plunging sheet bubble size distributions were obtained utilizing methods described previously by Deane and Stokes (2002). In brief, bubble plumes were imaged a few centimeters from the side of the tank using a high-resolution digital camera (Nikon). The distribution of bubble sizes was then obtained through computer-aided analysis of the images. The cross-sectional area of individual bubbles within a selected image were determined and then transformed into equivalent spherical radii. This data combined with an estimate of the imaging volume formed the basis of the bubble size distributions presented in Fig. 4 .

The reference distribution for a laboratory plunging breaking wave from Deane and Stokes (2002) is in absolute units of bubbles $\mathrm{m}^{-3} \mu \mathrm{m}^{-1}$ radius increment, which is standard 


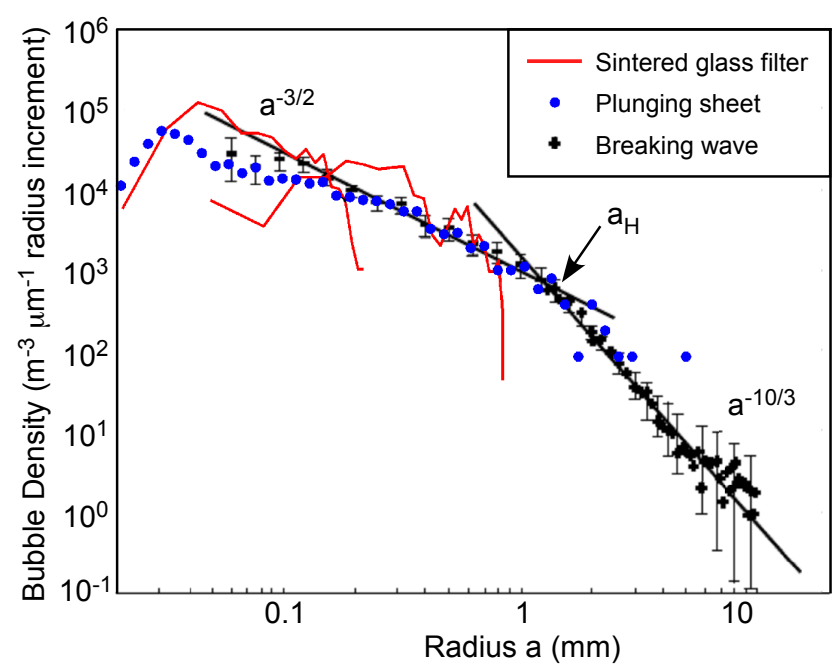

Fig. 4. Intercomparison of bubble size distributions from a laboratory breaking wave, the plunging sheet in the MART system and two distributions from sintered glass filters. The breaking wave distribution is in absolute units; the plunging sheet and sintered glass filter bubble distributions have been scaled as described in the text. The error bars on the breaking wave distribution show one std dev from a sample of 225 images from 14 breaking events (Deane and Stokes, 2002).

for the oceanographic literature. The absolute level of the distributions for sintered glass filters and plunging water were variable, depending on air flow, plunging sheet height and roughness, among other factors. To facilitate comparison with the breaking wave, the bubble size distributions for the sintered glass filters and plunging waterfall were first converted to probability density functions (PDFs) and then scaled by $5.6 \times 10^{6}$. The scaling factor was determined to be the value which brought the plunging waterfall and breaking wave distributions into agreement at a bubble radius of $<1 \mathrm{~mm}$.

\subsection{Aerosol size distributions and residence time}

Particle size distributions (PSDs) were determined by a commercially available TSI Scanning Mobility Particle Sizer (SMPS) and Aerodynamic Particle Sizer (APS). The SMPS measures particle mobility diameter $\left(d_{\mathrm{m}}\right)$ by scanning voltages through a TSI electrostatic classifier with differential mobility analyzer (DMA) column (Model 3080). Sampled particles are directed past a $508 \mu \mathrm{m}$ impactor to remove particles too large for analysis and into the DMA column, which separates particles by electrical mobility. The range of particle sizes which can be analyzed and the transfer function of the DMA is dependent on the voltage applied to the central rod and the aerosol and sheath flow rates, which were set at 0.4 and $4.0 \mathrm{~L} \mathrm{~min}^{-1}$, respectively. Particles selected in the DMA are injected into a condensation particle counter (TSI
Model 3010), which counts the particles over a range of size bins.

The APS (TSI Model 3321) determines the aerodynamic diameter $\left(d_{\mathrm{a}}\right)$ of particles in the 0.542 to $20 \mu \mathrm{m}$ range by measuring particle time-of-flight. Particles were sampled at $5.0 \mathrm{~L} \mathrm{~min}^{-1}$ (1.0 and $4.0 \mathrm{~L} \mathrm{~min}^{-1}$, aerosol and sheath flow rates, respectively). To determine $d_{\mathrm{a}}$, particles enter the inlet of the APS and pass between two separate paths of a CW laser split with a beamsplitter.

For both the SMPS and APS analysis, particles passed through silica gel diffusion driers, where they were dried to an $\mathrm{RH}$ of $15 \pm 10 \%$. The $d_{\mathrm{m}}$ and $d_{\mathrm{a}}$ size distributions recorded were merged to obtain a geometric physical diameter $\left(d_{\mathrm{p}}\right)$ size distribution. For the purposes of merging, particles sized by the SMPS were assumed to be of a spherical geometry, which allows for the relation:

$d_{\mathrm{m}}=d_{\mathrm{p}}$

Particles sized by the APS were assigned an effective density, $\rho_{\text {eff }}$, of $1.8 \mathrm{~g} \mathrm{~cm}^{-3}$, a value determined experimentally, which allows for conversion based on the relation:

$d_{\mathrm{p}}=\frac{d_{\mathrm{a}}}{\sqrt{\frac{\rho_{\mathrm{eff}}}{\rho_{0}}}}$.

with $\rho_{0}$ equal to unit density (i.e. $1 \mathrm{~g} \mathrm{~cm}^{-3}$ ). Both instruments had their resolution set to 32 bins per decade for consistency in merging. The SMPS tends to undercount particles at the high end of the distribution due to the cut-off from the particle impactor, while the APS can undercount particles at the low end due to poor scattering efficiency of the smallest particles. As a result, particle bins in the overlapping size region of the two methods were subsequently removed, excluding the largest and smallest bins of the SMPS and APS, respectively (Fig. 5). Because of this, caution is required in any detailed analysis of the overlap region between the two measurement methods, at or around $700 \mathrm{~nm}$ (Fig. 5).

During MART operation, carrier gas (either $\mathrm{N}_{2}$ or synthetic air) is supplied to the sealed tank at flow rates ranging between 1-10 slpm depending on instrument sampling requirements. The carrier gas flow, combined with particle deposition within the tank determine the average lifetime of a particle in the system prior to sampling. The e-folding time with respect to mixing is set by the headspace volume $(90 \mathrm{~L})$ and the carrier gas flow rate. For the three flow rates studied here $(1,3$, and 6 slpm) the average particle lifetime with respect to mixing are 90,30 , and 15 min, respectively. To assess deposition within the tank, we arrest plunging and particle production and monitor the decay in the size dependent number concentration. Size dependent decay rates are shown in Fig. 6 as a function of carrier gas flow. For the decay analysis, we use an Ultra High Sensitivity Aerosol Spectrometer (UHSAS) operating at $1 \mathrm{~Hz}$ for the submicron size distributions (Cai, 2008). The deviation in the decay from that 


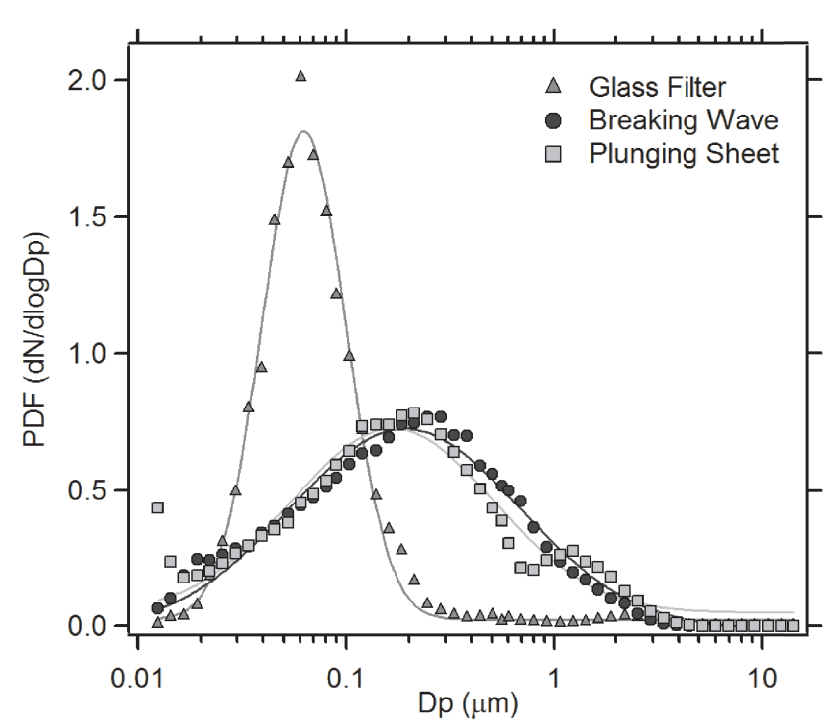

Fig. 5. Probability density functions of Sea Spray Aerosol (SSA) number distributions generated by the plunging sheet, breaking waves in a laboratory flume and sintered glass filters. The SSA particle diameter was measured at $15 \pm 10 \%$ relative humidity.

determined from mixing alone is a low-bound on particle deposition within the tank. Actual deposition rates are likely faster when the plunging waterfall is on. As shown in Fig. 6, particle deposition is strongly size dependent, where the observed particle lifetimes span between 2 and 63 min for a carrier gas flow rate of $1 \mathrm{slpm}$.

Particle lifetime with respect to deposition $\left(\tau_{\mathrm{DEP}}\right)$ is calculated from the observed lifetime ( $\left.\tau_{\mathrm{OBS}}\right)$ and that expected from mixing ( $\left.\tau_{\text {MIX }}\right)$ via Eq. (3) and shown in Fig. 7b.

$$
\frac{1}{\tau_{\mathrm{OBS}}}=\frac{1}{\tau_{\mathrm{DEP}}}+\frac{1}{\tau_{\mathrm{MIX}}}
$$

As expected, the in-tank deposition is strongly dependent on particle size, where particles with diameters greater than $2 \mu \mathrm{m}$ have $\tau_{\text {DEP }}$ as small as $2 \mathrm{~min}$, while particles in the size window of $60-200 \mathrm{~nm}$ display $\tau_{\text {DEP }}$ that is $2-3$ times $\tau_{\mathrm{MIX}}\left(\tau_{\mathrm{DEP}}=113-209 \mathrm{~min}\right)$. Further, $\tau_{\mathrm{DEP}}$ is dependent on the carrier gas flow rate, with increased deposition rates at higher carrier gas flows.

As a result, bias in the measured size distribution is expected for particles where $\tau_{\mathrm{DEP}}$ is significantly smaller than $\tau_{\mathrm{MIX}}\left(\right.$ e.g., $d_{\mathrm{p}}>2 \mu \mathrm{m} ; \tau_{\mathrm{DEP}}=1.5 \mathrm{~min}$ and $\tau_{\mathrm{MIX}}=90 \mathrm{~min}$ for 1 slpm carrier gas flow), highlighting the importance of using size dependent, empirical corrections when determining the size distribution of nascent SSA. Total number, surface area, and mass concentrations are dependent on the choice of carrier gas flow as shown in Table 1. Given fast in-tank deposition of larger particles, enhancements in surface area and mass (carried by the larger particles) are less pronounced at low carrier gas flow rates than would be expected from the observed increase in particle number.
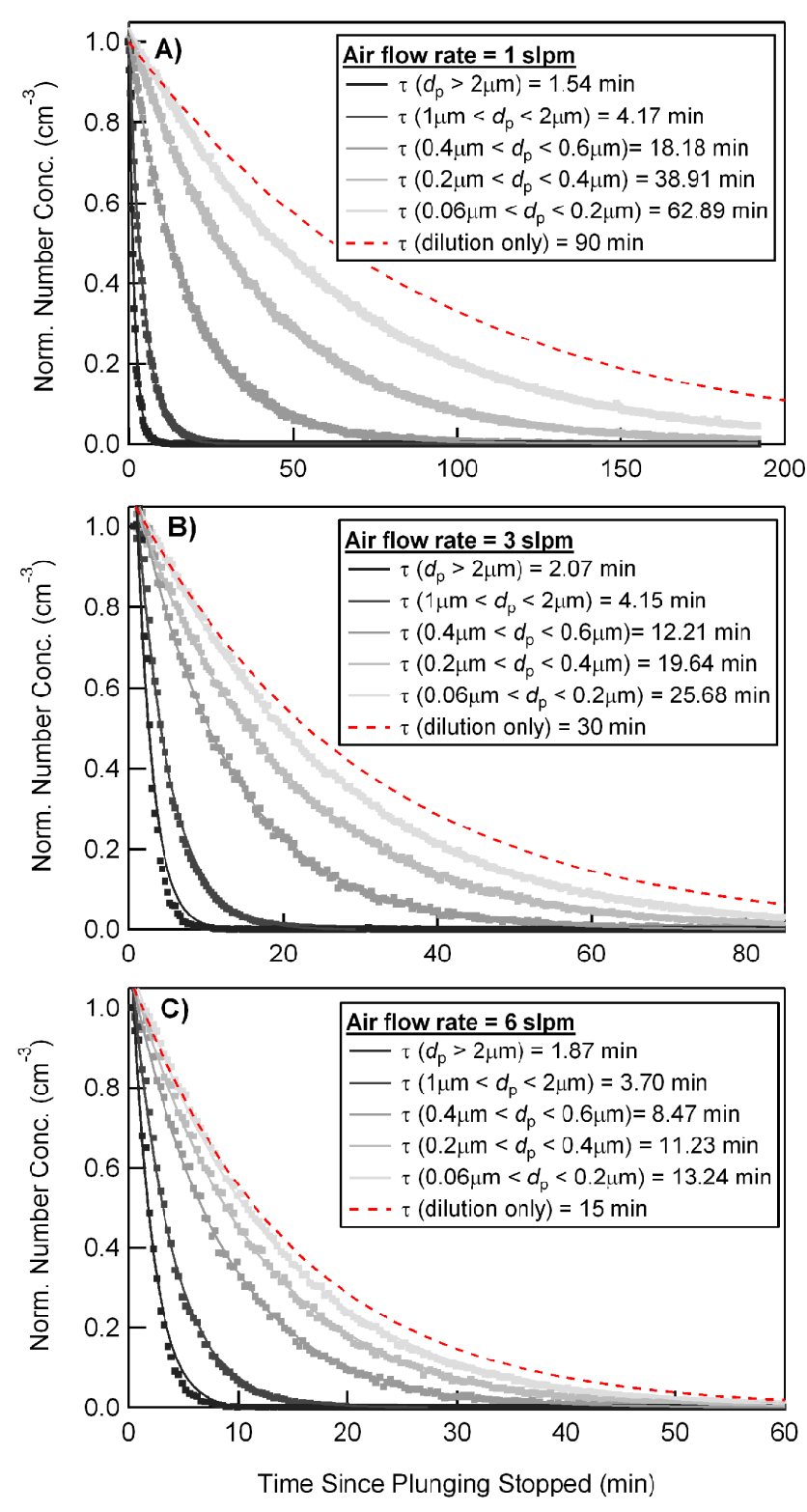

Fig. 6. Normalized size dependent decay rates in particle number concentration $\left(\mathrm{cm}^{-3}\right)$ for three different dilution air flow conditions: 1 slpm (A), 3 slpm (B), and 6 slpm (C) as measured following the suspension of in tank plunging. The associated e-folding lifetimes $(\tau)$ for each flow condition and size regime are included in the legend alongside the expected decay rates from dilution alone.

\subsection{Monitoring performance characteristics}

The air entrained by the plunging waterfall was monitored throughout the experiment by analyzing the underwater noise radiated by newly formed bubbles within the plumes (Deane and Stokes, 2010). The acoustic signature of the plunging jet and forming bubble plume is characteristic of particular pump and flow conditions and by monitoring the sound production we can ensure that these flow conditions are 
Table 1. Steady-state number, surface area, and mass concentrations measured as a function of the supplied synthetic air to the portable tank. The reported value represents the mean and standard deviation $(1 \sigma)$. The mass concentration assumes a particle density of $1.8 \mathrm{~g} \mathrm{~cm}{ }^{-3}$.

\begin{tabular}{|c|c|c|c|c|c|c|}
\hline \multirow[t]{2}{*}{$\begin{array}{l}\text { Flow Rate } \\
\text { (slpm) }\end{array}$} & \multicolumn{2}{|c|}{$\begin{array}{l}\text { Number Concentration } \\
\left(\mathrm{cm}^{-3}\right)\end{array}$} & \multicolumn{2}{|c|}{$\begin{array}{l}\text { Surface Area Concentration } \\
\left(\mu \mathrm{m}^{2} \mathrm{~cm}^{-3}\right)\end{array}$} & \multicolumn{2}{|c|}{$\begin{array}{l}\text { Mass Concentration } \\
\quad\left(\mu \mathrm{g} \mathrm{m}^{-3}\right)\end{array}$} \\
\hline & Submicron & Supermicron & Submicron & Supermicron & Submicron & Supermicror \\
\hline 1 & $6288 \pm$ & 36 & 9 & & 3 & 115 \\
\hline 3 & $5006 \pm 30$ & $346 \pm 14$ & $1263 \pm 14$ & $2807 \pm 215$ & $192 \pm 3$ & $1734 \pm 18$ \\
\hline 6 & $3698 \pm 68$ & $288 \pm 10$ & $992 \pm 23$ & $2232 \pm 119$ & $154 \pm 4$ & $1290 \pm 92$ \\
\hline
\end{tabular}

repeatable over time. The acoustic measurements were conducted using a hydrophone (ITC 1089d) placed a few centimeters from the bubble plumes and analyzed with a Stanford Research Systems SR785 Dynamic Signal Analyzer. Acoustic reverberation within the tank makes a quantitative analysis of the noise problematic, however, by keeping the hydrophone position relative to the plume fixed and generating a reference acoustic spectrum at the beginning of an experimental run, it is possible to detect changes in air entrainment conditions over time. In addition to the acoustic monitoring, the flow rate of water supplied to the spillway is measured using a digital flow meter downstream of the circulation pump and any variation in flow can be adjusted using the shunt flow valve.

In Fig. 8, the acoustic spectrum recorded at three different plunging sheet flow rates $\left(0.6,0.75\right.$ and $\left.0.95 \mathrm{~L} \mathrm{~s}^{-1}\right)$, each at three different times during an experimental session is shown. Even though the sound being generated by each plunging sheet is from a seemingly random ensemble of ringing bubbles in a turbulent flow field, the acoustic power in certain frequency bands (e.g., $4 \mathrm{kHz}$ ) is relatively conserved at each flow rate and set of tank conditions as shown by the clustering of the red, green and blue lines in Fig. 8. By monitoring the acoustic spectrum for large variations, the MART system can be configured to replicate bubble plume production in separate experiments (i.e., by adjusting the flow rate, height of the plunging sheet, angle of the spillway, duty cycle of the solenoid valves) and thus consistently replicate the aerosol source; therefore, by regularly monitoring the acoustic spectrum during a experimental session, any drift in production mechanism attributable to changes in the bubble plume can be noted, adjusted or compensated for.

\section{Comparison of MART to other generation methods}

As noted by Sellegri et al. (2006) and Fuentes et al. (2010), a plunging water jet best replicates the bubble plumes generated by an oceanic whitecap. Comparison of the bubble plume formed by the MART system to those generated by air flow through sintered glass filters and to those formed in oceanic waves and within a large laboratory wave channel (Figs. 1 and 4) illustrates that a plunging sheet of water forms
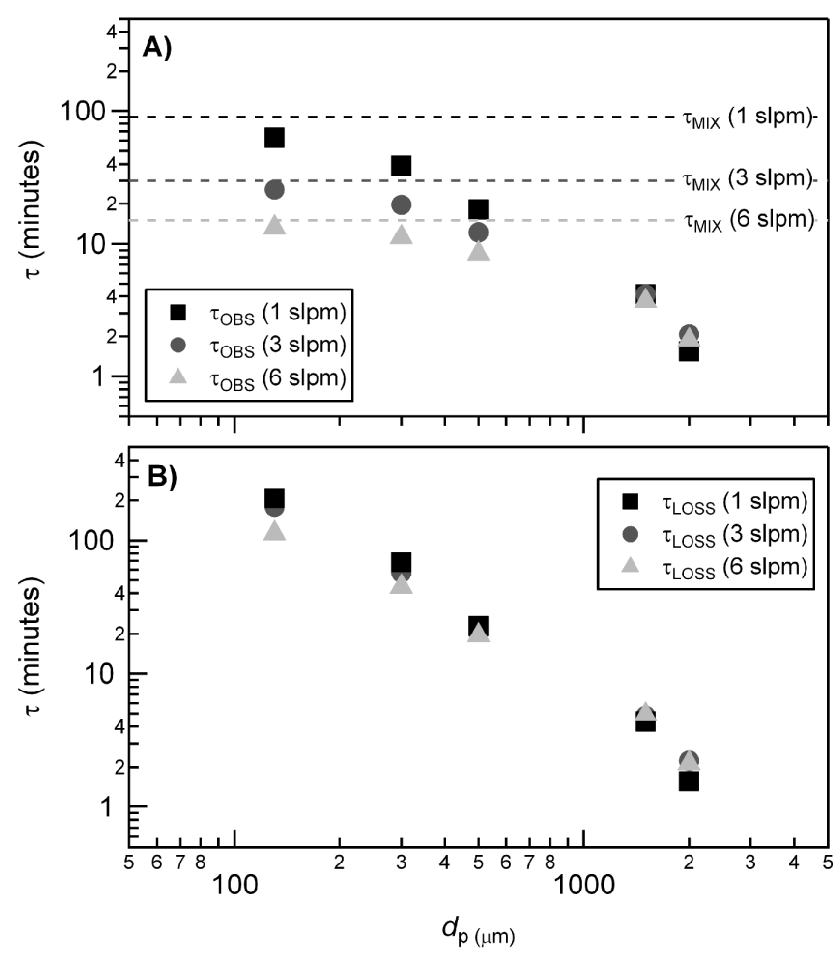

Fig. 7. (A) Observed lifetime as calculated from the decays shown in Fig. 6 as a function of particle size. For reference, the size independent lifetimes due to dilution alone are shown with dashed lines. (B) Calculated size dependent lifetime with respect to deposition within the tank for the three air flow dilution rates.

a broader spectrum of bubble sizes than the sintered glass filters tested, including critical bubbles larger than about $1 \mathrm{~mm}$ in radius. The slopes of the bubble density size spectrum in the MART plumes are very similar to the slopes of oceanic and laboratory breaking waves at sizes smaller and larger than the Hinze scale $\left(a_{\mathrm{H}}\right)$. The bubble plumes generated by the sintered filters have a much narrower size spectrum and tend not to include bubbles larger than about $800 \mu \mathrm{m}$ radius.

By using a much larger volume tank than that used by Fuentes et al. (2010), the bubble plumes generated by the plunging sheet can penetrate 20 to $30 \mathrm{~cm}$ beneath the water surface which is similar to the penetration depths of plumes 


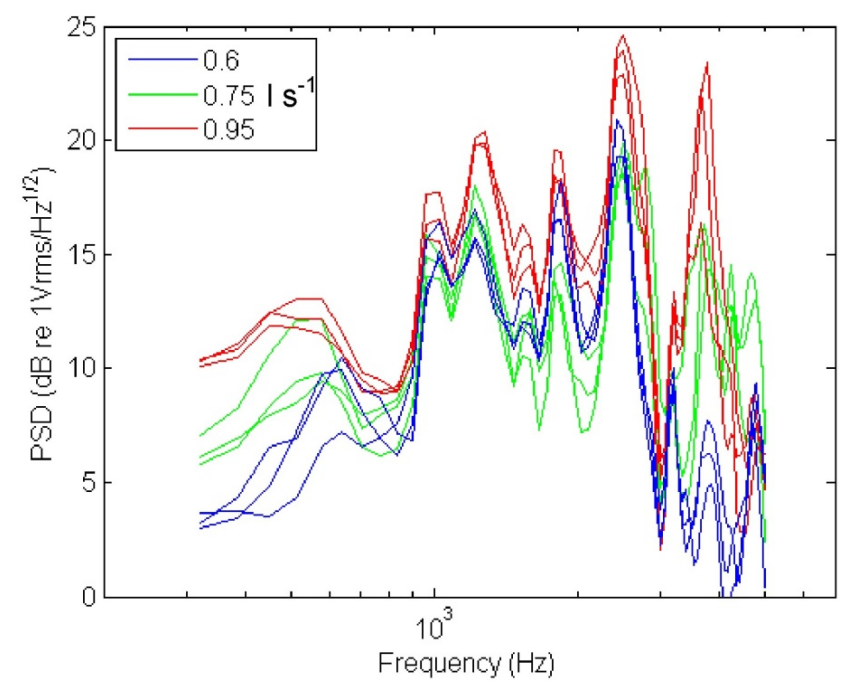

Fig. 8. Spectrum of the voltage output from a miniature hydrophone (ITC 1089d) mounted approximately $5 \mathrm{~cm}$ from the end of the plunging sheet. There are 9 spectra shown in the plot consisting of three replicas for three different flow rates as indicated in the legend. The variation of the spectra with frequency is a function of both resonances within the tank and variation in the sound radiated by the bubble plume. Despite variability within an ensemble for a fixed flow rate, distinct differences in the spectra can be seen between flow rates.

generated by spilling breakers in the lab and ocean (Deane and Stokes, 2002; Melville, 1996). The intermittent cycling of the plunging jet in the MART system allows the bubble plume and resulting surface foam patch (Fig. 3) to evolve over time creating a bubble and aerosol source that is a closer match to the decaying patches of foam produced by whitecaps than that provided by constant, stationary jets. The importance of decaying foams (as opposed to pseudo steady state foams, for which decay rates are matched by bubble entrainment rates) remains an open question, but may be important. For example, the jet drop production mechanism may be somewhat suppressed in steady state foams if they are more than a single bubble layer thick because of the top layer of foam film absorbing jet drop aerosols produced at the airwater interface. Foams allowed to decay even if they are initially three-dimensional in structure, will eventually devolve into two-dimensional rafts of bubbles which will not suppress jet drops. The MART system is currently being used to examine these foam dynamics. By manually activating the plunging sheet to produce isolated foam patches or changing the TR53122 timing relay to one enabling longer delay times between plunging, the properties of surface foam patches and SSA production as they evolve over time are being studied.

The particle number distribution measured using the MART system is broader and peaks at a significantly larger diameter as compared with particle number distributions obtained using sintered glass filters (Fig. 5). Though similar to the size distribution obtained by Fuentes et al. (2010), it is notable that the particle number distribution obtained using the MART system has less pronounced characteristics of sub-100 nm modes, with the dominant number distribution mode around $200 \mathrm{~nm}$, broadly tailing off to both larger and smaller sizes. Similarly, the particle number distribution generated by the plunging jet, or "weir" of Sellegri et al. (2006) peaks at approximately $100 \mathrm{~nm}$, with a secondary peak at approximately $350 \mathrm{~nm}$, similar to their medium-sized glass frit, and without a significant contribution of super-micron sized particles evident in the MART distribution. This result is consistent with the broad bubble size spectrum and accurate representation of bubbles larger that $1 \mathrm{~mm}$ that is achieved by MART. Particle number distributions measured in the MART system are in strong agreement with those previously measured from breaking waves in the Scripps Institution of Oceanography Hydraulics Laboratory (Prather et al., 2013). These measurements highlight the importance of an accurate representation of bubble formation processes in the creation of sea-spray aerosol in the laboratory.

\section{Conclusions}

In order to faithfully reproduce the aerosols created by breaking oceanic waves any surrogate system must mimic the complex two-phase flows, bubble plumes and surface foam patches naturally generated during whitecap formation. These conditions can be replicated in large seawater breaking wave channels; however, these facilities are not readily available, and due to their large volume it is extremely difficult to satisfactorily enclose them for high fidelity aerosol sampling and to carefully control the environmental conditions within them. Sintered glass filters (frits) sparged with air in an enclosed tank produce controllable plumes, however the bubbles produced are constrained to a size spectrum that is considerably narrower than the spectrum observed in laboratory and open ocean breaking waves. In order to reproduce the broad spectrum of bubbles from a breaking wave would require injecting air through multiple frits of varying size and varying injection rate, but even then the slopes of the bubble distributions produced would need to reflect the change in slope observed about the Hinze scale in natural distributions.

When creating plumes using plunging water, it is important that the falling sheet or jet have the appropriate scale of surface roughness before impacting the water surface in order to create the correct sized voids along the air-water interface (Zhu et al., 2000). The larger voids in particular are critical for producing the correct plume bubble size distribution that includes bubbles larger than the Hinze scale. Stationary, narrow cross-sectional area and high velocity jets may not entrain large bubbles characteristic of whitecaps without the correct scale of disturbances on their surface before impacting the water. 
It may be important that any bubble plume creation mechanism provide the correct intermittency in production. Natural plumes and the resulting surface foam patches evolve over a time scale of seconds to tens of seconds. Continuous jets impacting the surface at a fixed location create subsurface flow fields unlike breaking events. Continuous sparging of air through frits or air entrainment by continuous jets can also create three-dimensional surface foams that do not evolve and dissipate like within natural whitecaps and then can bias physical and chemical attributes of the aerosols created when the bubbles rupture (submitted Science paper).

The resulting particle size distribution generated within the MART system closely resembles that generated from breaking waves within the SIO glass-walled wave channel. Confining the bubble generation to a smaller headspace air volume $(<50 \mathrm{~L})$ as compared to the wave channel, permits a significant increase in particle number concentrations (from 100 to greater than 5000 particles $\mathrm{cm}^{-3}$, for the wave channel and MART system, respectively). As a result, the MART system enables a wide array of measurements (e.g., size resolved hygroscopicity and heterogeneous reactivity) that are not feasible at the low number concentrations produced in the wave channel.

The MART system provides many benefits for the controlled study of the chemistry and physics of marine bubbles, foam and aerosols. Because the air entrainment processes are monitored, experiments are repeatable even while environmental variables, like the seawater and atmospheric chemistry and the physical forcing mechanisms controlling the plume dynamics are manipulated. Furthermore, the MART provides a standardized, easily fabricated, portable aerosol source for studies across separate labs or for shipboard use while at sea.

Acknowledgements. The authors would like to thank the SIO Hydraulics Facility and the NSF-funded Center for Aerosol Impacts on Climate and the Environment (CIACE). O. S. Ryder gratefully acknowledges a graduate fellowship from the NSF Graduate Student Research Program.

Edited by: H. Herrmann

\section{References}

Bezzabotnov, V. S., Bortkovskii, R. S., and Timanovskii, D. F.: On the structure of the two-phase medium generated at windwave breaking, Izvestiya Akedemii Nauk SSR, Fizika Atmosfery I Okeana, 22, 1186-1193, 1986.

Bowyer, P. A.: Video measurements of near-surface bubble spectra, J. Geophys. Res., 106, 14179-14190, 2001.

Braban, C. F., Adams, J. W., Rodriguez, D., Cox, R. E., Crowley, J. N., and Schuster, G.: Heterogeneous reactions of $\mathrm{HOI}, \mathrm{ICl}$ and IBr on sea salt and sea salt proxies, Phys. Chem. Chem. Phys., 9, 3136-3148, 2007.
Cai, Y., Montague, D. C., Mooiweer-Bryan, W., and Deshler, T.: Performance Characteristics of the Ultra High Sensitivity Aerosol Spectrometer for Particles between 55 and 800nm: Laboratory and Field Studies, J. Aerosol Sci., 39, 759-769, 2008.

Cipriano, R. J. and Blanchard, D.: Bubble and Aerosol Spectra Produced by a Laboratory "Breaking Wave", J. Geophys. Res., 86, 8085-8092, 1981.

Cloke, J., McKay, W. A., and Liss, P. S.: Laboratory investigations into the effect of marine organic material on the sea-salt aerosol generated by bubble bursting, Mar. Chem., 34, 77-95, 1991.

Deane, G. B. and Stokes, M. D.: Scale dependence in bubble creation mechanisms in breaking waves, Nature, 418, 839-844, 2002.

Deane, G. B. and Stokes, M. D.: Model calculations of the underwater noise of breaking waves and comparison with experiment, J. Acoust. Soc. Am., 127, 3394-3410, 2010.

de Leeuw, G. and Cohen, L.: Bubble size distributions on the North Atlantic and North Sea, Gas Transfer at Water Surfaces, Geophys. Monogr., 127, 271-277, 2002.

de Leeuw, G. and Leifer, I.: Bubbles outside the plume during the LUMINY wind-wave experiment, Gas Transfer at Water Surfaces, Geophys. Monogr., 127, 295-301, 2002.

Facchini, M. C., Rinaldi, M., Decesari, S., Carbone, C., Finessi, E., Mircea, M., Fuzzi, S., Ceburnis, D., Flanagan, R., Nilsson, E. D, de Leeuw, G., Martino, M., Woeltjen, J., and O'Dowd, C. D.: Primary submicron marine aerosol dominated by insoluble organic colloids and aggregates, Geophys. Res. Lett., 35, L17814, doi:10.1029/2008GL034210, 2008.

Fuentes, E., Coe, H., Green, D., de Leeuw, G., and McFiggans, G.: Laboratory-generated primary marine aerosol via bubblebursting and atomization, Atmos. Meas. Tech., 3, 141-162, doi:10.5194/amt-3-141-2010, 2010.

Herrero, S.: Bear attacks their causes and avoidance, Hurtig, McClelland \& Stewart Co. Publ. Toronto, 1985.

Hultin, K. A. H., Nilsson, E. D., Krejci, R., Martensson, E. M., Hagstrom, A., and de Leeuw, G.: In situ laboratory sea spray production during the MAP 2006 cruise on the North East Atlantic, J. Geophys. Res., 115, D06201, doi:10.1029/2009JD012522, 2010.

Keene, W. C., Maring, H. , Maben, J. R., Kieber, D. J., Pszenny, A. A. P., Dahl, E. E., Izaguirre, M. A., Davis, A. J., Long, M S., Zhou, X., Smoydzin, L., and Sander, R.: Chemical and physical characteristics of nascent aerosols produced by bursting bubbles at a model air-sea interface, J. Geophys. Res., 112, D21202, doi:10.1029/2007JD008464, 2007.

Lamarre, E. and Melville, W. K.: Void-fraction measurements and sound-speed fields in bubble plumes generated by breaking waves, J. Acous. Soc. Am., 95, 1317-1328, 1994.

Leifer, I. and de Leeuw, G.: Bubble measurments in breaking-wave generated bubble plumes during the LUMINY wind-wave experiment, Gas Transfer at Water Surfaces, Geophys. Monogr., 127, 303-309, 2002.

Leifer, I. and de Leeuw, G.: Bubbles generated from windsteepened breaking waves: 1 . bubble plume bubbles, J. Geophys Res., 111, C06020, doi:10.1029/2004JC00267, 2006.

Leighton, T. G., Phelps, A. D., and Ramble, G. D.: Acoustic bubble sizing: from the laboratory to the surf zone trials, Acoustics Bull., May, 5-9, 1996. 
Lewis, E. R. and Schwartz, S. E.: Sea Salt Aerosol Production: Mechanisms, Methods, Measurements, and Models: A Critical Review, American Geophysical Union, Washington, DC, 2004.

Loewen, M. R., O’Dor, M. A., and Skafel, M. G.: Laboratory measurements of bubble size distributions beneath breaking waves, in: Air-Sea Gas Transfer, Third International Symposium on AirWater gas transfer, edited by: Jahne, B. and Monahan, E. C., AEON Verlag \& Studio, Germany, 337-345, 1995.

Martensson, E. M., Nilsson, E. D., Cohen, L. H., and de Leeuw, G.: Laboratory simulations and parameterization of the primary marine aerosol production, J. Geophys. Res., 108, 4297, doi:10.1029/2002JD002263, 2003.

McNeill, V. F., Patterson, J., Wolfe, G. M., and Thornton, J. A.: The effect of varying levels of surfactant on the reactive uptake of $\mathrm{N}_{2} \mathrm{O}_{5}$ to aqueous aerosol, Atmos. Chem. Phys., 6, 1635-1644, doi:10.5194/acp-6-1635-2006, 2006.

Melville, W. K.: The role of surface-wave breaking in airsea interaction, Ann. Rev. Fluid Mech., 28, 279-321, doi:10.1146/annurev.fl.28.010196.001431, 1996.

Monahan, E. C. and Zeitlow, C. R.: Laboratory comparisons of fresh-water and salt-water whitecaps, J. Geophys. Res., 74, 6961-6966, 1969.

Nicolson, M.: The interaction between floating particles, Math. Proc. Cambridge Philos. Soc., 45, 288-295, 1949.

Niedermeier, D., Wex, H., Voigtländer, J., Stratmann, F., Brüggemann, E., Kiselev, A., Henk, H., and Heintzenberg, J.: LACIS-measurements and parameterization of sea-salt particle hygroscopic growth and activation, Atmos. Chem. Phys., 8, 579590, doi:10.5194/acp-8-579-2008, 2008.

Prather, K., Bertram, T., Grassian, V., Deane, G., Stokes, M., DeMott, P., Aluwihare, L., Palenik, B., Azam, F., Seinfeld, J., Moffet, R., Molina, M., Cappa, C., Geiger, F., Roberts, G., Russell, L., Ault, A., Baltrusaitis, J., Collins, D., Corrigan, C., CuadraRodriguez, L., Ebben, C., Forestieri, S., Guasco, T., Hersey, S., Kim, M., Lambert, W., Modini, R., Mui, R., Pedler, B., Ruppel, M., Ryder, O., Schoepp, N., Sullivan, R., and Zhao, D.: Bringing the ocean into the laboratory: Impacts of chemical complexity of sea spray aerosol on climate relevant properties, Proc. Natl. Aca. Sci., 110, D0262110, doi:10.1073/pnas.1300262110, 2013.
Riziq, A., Erlick, C., Dinar, E., and Rudich, Y.: Optical properties of absorbing and non-absorbing aerosols retrieved by cavity ring down (CRD) spectroscopy, Atmos. Chem. Phys., 7, 1523-1536, doi:10.5194/acp-7-1523-2007, 2007.

Saint-James, A.: Physical chemistry in foam drainage and coarsening, Soft Matter, 2, 836-849, 2006.

Saul, T. D., Tolocka, M. P., and Johnston, M. V.: Reactive uptake of nitric acid onto sodium chloride aerosols across a wide range of relative humidities, J. Phys. Chem. A, 110, 7614-7620, 2006.

Sellegri, K., O’Dowd, C. D., Yoon, Y. J., Jennings, S. G., and de Leeuw, G.: Surfactants and submicron sea spray generation, J. Geophys. Res., 111, D22215, doi:10.1029/2005JD006658, 2006.

Solomon, S., Qin, D., Manning, M., Chen, Z., Marquis, M., Averyt, K., Tignor, M., Miller, H. (Eds.): IPCC, 2007: Climate Change 2007: The Physical Science Basis, Contribution of Working Group I to the Fourth Assessment, Cambridge University Press, 2007.

Stokes, M. D., Deane, G., Vagle, S., and Farmer, D.: Measurements of large bubbles in open-ocean whitecaps, Gas Transfer at Water Surfaces, Geophys. Monogr., 127, 279-284, 2002.

Svenningsson, B., Rissler, J., Swietlicki, E., Mircea, M., Bilde, M., Facchini, M. C., Decesari, S., Fuzzi, S., Zhou, J., Mønster, J., and Rosenørn, T.: Hygroscopic growth and critical supersaturations for mixed aerosol particles of inorganic and organic compounds of atmospheric relevance, Atmos. Chem. Phys., 6, 1937-1952, doi:10.5194/acp-6-1937-2006, 2006.

Taketani, F., Kanaya, Y., and Akimoto, H., Heterogeneous loss of $\mathrm{HO}_{2}$ by $\mathrm{KCl}$, synthetic sea salt, and natural seawater aerosol particles, Atmos. Environ., 43, 1660-1665, 2009.

Tyree, C. A., Hellion, V. M., Alexandrova, O. A., and Allen, J. O.: Foam droplets generated from natural and artificial seawaters, J. Geophys. Res., 112, D12204, doi:10.1029/2006JD007729, 2007.

Wise, M. E., Freney, E. J., Tyree, C. A., Allen, J. O., Martin, S. T., Russel, L. M., and Buseck, P. R.: Hygroscopic behaviour and liquid-layer composition of aerosol particles generated from natural and artificial seawater, J. Geophys. Res., 114, D03201, doi:10.1029/2008JA013848, 2009.

Zhu, Y., Oguz, H. N., and Prosperetti, A.: On the mechanism of air entrainment by liquid jets at a free surface, J. Fluid Mech., 404, 151-177, 2000. 